\title{
CORRECTION
}

\section{Correction to: Stenotrophomonas nematodicola sp. nov., isolated from Caenorhabditis elegans}

\author{
Xuyang Wei ${ }^{1}$. Shengwei Lei ${ }^{1} \cdot$ Yang Deng ${ }^{2} \cdot$ Yuqin Zhang ${ }^{2} \cdot$ Lin Zhang $^{1} \cdot$ Qiuhong Niu ${ }^{1} \mathbb{C}$
}

Published online: 7 February 2022

○) Springer-Verlag GmbH Germany, part of Springer Nature 2022

\section{Correction to: \\ Archives of Microbiology (2021) 203:6197-6202 \\ https://doi.org/10.1007/s00203-021-02586-y}

In the original article, the correct KCTC is 82903 .

The original article has been corrected.

Publisher's Note Springer Nature remains neutral with regard to jurisdictional claims in published maps and institutional affiliations.

The original article can be found online at https://doi.org/10.1007/ s00203-021-02586-y.

\section{Lin Zhang}

zhanglin201207@163.com

$\triangle$ Qiuhong Niu

qiuhongniu723@163.com

1 College of Life Science and Agricultural Engineering, Nanyang Normal University, 1638 Wolong Road, Nanyang 473061, Henan, China

2 Institute of Medicinal Biotechnology, Chinese Academy of Medical Sciences \& Peking Union Medical College, Beijing 100050, China 